\title{
Investigating the Effects of Subjective Norms and Trialability on English Teachers`Attitude toward the Use of Technology
}

\author{
Somaye Davoodi, ${ }^{1}$ Leila Akbarpour, ${ }^{2 *}$ Ehsan Hadipour ${ }^{3}$ \\ 1, 2, 3 Department of English Language, Shiraz Branch, Islamic Azad University, Shiraz - Iran
}

\begin{abstract}
Despite the availability of many technological resources in academic settings and their determinant effect in the improvement of teaching and learning, teachers rarely use them. The aim of the present study is to investigate the effect of psychological variables on teachers' attitudes regarding technology use. In this research, most applicable models like the 'technology acceptance model', 'theory of reasoned action', and 'innovation diffusion theory' are used as the foundation for developing a conceptual framework. Variables such as 'perceived usefulness', 'perceived ease of use', 'trialability', 'subjective norms', and 'attitude' are recaptured from these models. The participants were high school English language teachers in Shiraz. The researcher used stratified sampling to identify a representative sample from the population. The present study was administered by using five questionnaires to assess variables. The data were analyzed by means of path analysis. According to the obtained results, perceived ease of use is affected by subjective norms and trialability, which in turn influences the attitude of teachers toward using technology in their teachings. The results suggest that the most influential factor on attitude is trialability $(\beta=0.38)$ On the other hand, perceived usefulness has a significant, influential effect on attitude. Subjective norms have an indirect but important effect on attitude.
\end{abstract}

Article Information

Received 28 January 2020

Accepted 02 February 2020

Published February 22, 2021

Keywords: Attitude; perceived usefulness; perceived ease of use; trialability; subjective norm

\section{Introduction}

Advances in technology, especially information technology, have quickly changed the world and significantly affect many dimensions of human life, including education. Educational technology restyles the way teachers communicate and teach. New

*Corresponding Author: Leila Akbarpour (akbarpourleila@yahoo.com), Islamic Azad University, Shiraz Branch, northwest of Tang-e Qarah Pīrī, Shiraz, Iran technological tools enable teachers at any time to access new ways of teaching in multi-fold content areas and numerous formats. However, having these technological resources does not mean that they will be applied. To improve the efficient use of technology in teaching, English language teachers could concentrate on strategies such as combining previous teaching methods with new techniques in which technological devices could be used, utilizing computer software, and generating an interacting learning environment. The achievement of any technology use for teacher 
technical development is contingent upon teachers' acceptance and use of these instruments. As Davis (1989) says, the essential motivation for technology acceptance and use is the adopter's belief about the usefulness of the technology or the consequences of usage(Park, 2009). Therefore, a positive attitude towards the consequences or outcomes of technology use invokes a higher usage rate. Accordingly, this research attempts to evaluate the situation that concurrently exists in our schools, its effect on teachers' attitude towards using a computer in teaching and clarify the problems they encounter in using it. Thus, there is a need to investigate the factors influencing teachers' technology adoption and technology acceptance. Therefore, this study examined the effect of determinant factors affecting teachers' attitudes toward technology use. It utilizes the Technology Acceptance Model (TAM) and Theory of Reasoned Action (TRA). These approaches illustrate that human behavior mostly depends on an individual's characteristics.

Many prior studies have investigated various aspects of technological developments in English teaching solely from learners' point of view. This research examined technology acceptance from teachers' viewpoint. Although in various research works, the relations between technology acceptance variables had been considered, the present study tried to add some other variables to the technology acceptance model (TAM) and extend this model. Therefore, the hypothesized research model was based on TAM and some famous models like reasoned action theory.

Therefore, this study aimed at presenting a research model for examining English language teachers' acceptance and attitude. Proposing a conceptual framework, the present paper is based on theory of reasoned action, technology acceptance model, and social cognitive theory. The impacts of perceived usefulness, perceived ease of use, self-efficacy, and subjective norms on teachers' attitude toward technology acceptance and technology adoption are addressed in this study. The result of this research is believed to be beneficial for students, teachers, and administrators since the attitude of teachers toward technology use is among the most important factors that can determine the formal and informal syllabi in classes. This study may provide sensible benefits to schools and other scholastic settings in the successful design and performance of utilizing technology in education. As a result of the profits gained from the present study, the rate of information technology adoption could be increased by correction or adjustment. This research might play an important role in assisting the Iranian educational settings in incorporating technology in a way driven by pedagogical ambitions, institutional ideals, and student learning.

Several attitude theories and models have ascertained the interdependent relation between attitude and behavior. In 1975, Fishbein and Ajzen proposed the Theory of Reasoned Action (TRA). It is among the most functional theories of attitude. This theory is called the model of reasoned action due to its supposition that people's actions are mainly rational and based on analyzing existing information (Venkatesh \& Davis, 2000). Regarding the Theory of Reasoned Action, an individual's behavioral goals specify one's real manner. The behavioural goal is in turn specified 
by the individual's attitude regarding this behavior and subjective norms concerning the execution of this behavior (Smith, 2006). Behavioural goal is a degree of one's goal to act a particular behavior, attitude is an individual's positive or negative feeling about acting the objective behavior, and the subjective norm is a person's perception that most people who are appreciable to him/her think he or she should or should not carry out the behavior (Delice, 2009).

Davis in 1989 designed a theoretically justified model (Delice, 2009). He selected the Theory of Reasoned Action as the basis of his model (technology acceptance model) since it was working in diverse research fields like teaching, health, and social science. The Technology Acceptance Model was first proposed to detect the extent of technology adoption or use by individuals and organizations (Dastorani \& Khoshneshin, 2017). TAM has been widely considered as one of the most practical models in various fields. It has manifested great capability in explaining and forecasting user behavior regarding information technology. This feature has turned into the preferable model to examine the acceptance of e-learning (Park, 2009). There are four factors explaining technology usage in the original TAM: perceived ease of use (PEOU), perceived usefulness (PU), attitude, and intention to use (Yunus, 2014). Perceived ease of use involves the degree to which a person assumes that utilizing a particular system would be free of attempt, whereas perceived usefulness is demonstrated as the degree to which a person postulates that utilizing a specific system enhances his or her property (Davis, 1989). In the primary formulation of TAM, attitude performs a moderating role between the two mentioned variables (PEOU, PU) and the intention to use.

Another influential model in the field of technology acceptance is innovation diffusion theory. Innovation Diffusion Theory (IDT) is the foundation of most contemporary studies on innovation adoption and diffusion. This theory is generally used to explain and foresee adoption and diffusion behavior (Agarwal \& Prasad, 1997). It is the most popular theory on technical adjustment. IDT has been vastly used in a variety of fields like science, psychology, communication, shopping, the internet, and technology (Rogers, 1995). IDT contains five prominent innovation characteristics: compatibility (CPT), relative advantage (RAD), complexity (CPX), trialability, and observability. Compatibility is described as the level of correspondence between an innovation and users' accounts, experiences, and needs (Isaac, Abdullah, Ramayah, Mutahar, \& Alrajawy, 2016). Relative advantage is outlined as the degree to which an innovation is believed to be predominant to the idea it substituted (Rogers, 1995). Complexity refers to the recognition of how formidable the innovation is to perceive. It is conversely correlated with the rate of adoption of an innovation (Rogers, 1995). Trialability is the extent to which an innovation can be examined within a certain limitation. Trialability can also be described as the degree to which an innovation may be investigated within a restricted foundation (Shiau, Huang, Yang, \& Juang, 2018). Observability is the degree to which the influence of innovations can be perceived obviously by other people. These characteristics are used to illustrate end-user adoption of novel technologies and the 
procedure of making decisions (Lee, Hsieh, \& Hsu, 2011).

Tri Anni, Sunawan, and Haryono (2018), who investigated school teachers' intention to use technology, discovered that perceived ease of use and perceived usefulness positively impacted on the teachers' attitude toward the use of technology. This finding is asserted in the work of researchers such as Rabaa'i (2018) and Wingo, Ivankova, and Moss (2017). Dastorani and Khoshneshin (2017) conducted a study on Iranian university teachers' intention to use technology for educational purposes and found that the impact of perceived ease of use and perceived usefulness on attitude was significant. Yunus (2014), in a study on intention to utilize technology, discovered that compatibility and trialability had a salient effect on the intention to use via attitude. Contrary to these researchers, Ntemana and Olatokun (2012) considered lecturers' attitude toward technology use and found that among the five components of innovation diffusion theory, compatibility and trialability showed no relationship with attitude. Consequently, the first hypothesis is proposed:

1) Perceived usefulness, perceived ease of use, and trialability affect attitude toward using technology among high school English teachers.

Lee et al. (2011), in a study, showed the significant effect of perceived ease of use and trialability on perceived usefulness. The results of the study by Mutahar, Norzaidi, Ramayah, Isaac, and Alrajawy, (2017) was in line with Lee et al., (2011). Bourgonjon et al. (2013) did research in the field of game-based learning and asserted the strong effect of subjective norm on perceived usefulness. The result of this study was in line with Wingo et al., (2017), who did research about faculty perception of teaching online. In another research by Isaac et al., (2016) among employees in Yemen, the influential effect of perceived ease of use on perceived usefulness was confirmed. Dastorani and Khoshneshin (2017), in a review article, confirmed the effect of subjective norms on perceived usefulness. Consequently, the following second hypothesis is proposed for the purpose of the present work:

2) Trialability, subjective norm, and perceived ease of use affect the perceived usefulness of technology among high school English teachers.

According to Nan, Guo, and Chen (2008), the effect of trialability on perceived ease of use is significant. Lee et al. (2011) conducted research on the intention to use e-learning systems. In this study, perceived ease of use was indicated to be affected strongly by trialability. The results of the study by Tran and Cheng (2017) confirmed the impact of trialability on perceived ease of use. Park (2009) did a study on students' intention to use e-learning and reported the salient effect of subjective norm on perceived ease of use. Rabaa'i (2018) also found the strong effect of subjective norms on perceived ease of use. Consequently, the third hypothesis is proposed:

3) Trialability and subjective norm affect perceived ease of use of technology among high school English teachers.

Based on the theoretical and practical frameworks, we propose a conceptual framework for this study. Figure 1 illustrates this primary model. 


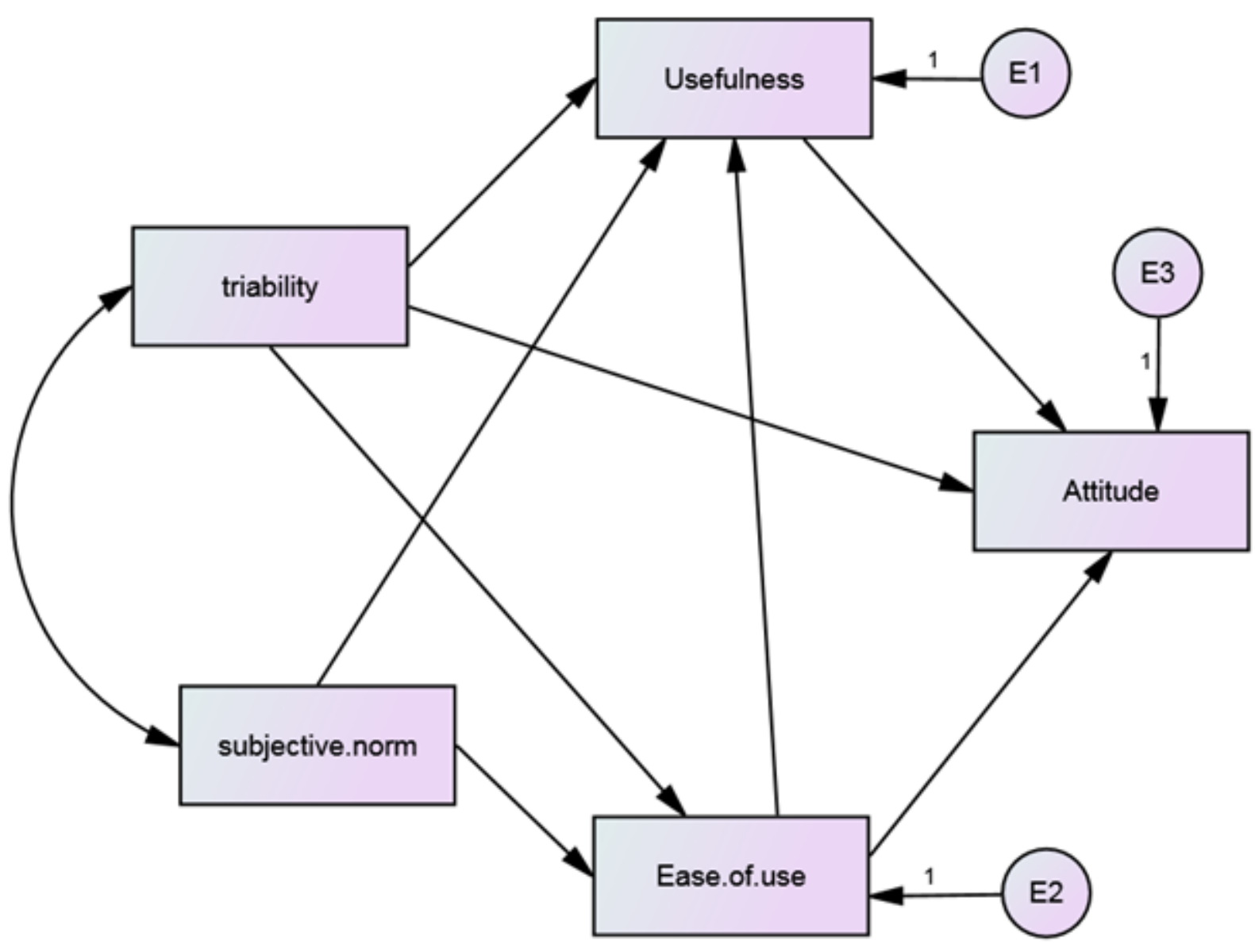

Figure 1. Conceptual framework of the study

\section{Method}

\section{Participants}

Participants in this study are all high school English teachers from four regions in Shiraz. In this study, urban high schools in Shiraz were selected. These schools include all public and private schools. This population includes 641 teachers. Because the population is unequal in four regions, the researcher utilized stratified sampling to determine a representative sample from the population. Krejcie \& Morgan's formula was used to assess the sample size. By utilizing this formula, the sample equals 242 teachers (Krejcie \& Morgan, 1970).

\section{Instrument}

Because questionnaires are among the most affordable ways to gather quantitative data and offer the highest possible response rate, the researcher decided to collect the research data by using questionnaires. Five questionnaires were used in this study. All of the five questionnaires were standard questionnaires that had been used in various studies. Because the numbers of items in each questionnaire were restricted, the researcher collected all five questionnaires in one. 
Fifteen attitude-related statements comprised section I that was about an attitude toward technology use. Teacher's attitudes towards the ICT scale were developed by Albirini (2006). The scale was synchronized from "strongly disagree" (1) to "strongly agree" (5). Junhong (2009) used this questionnaire in his article. He reported that the Cronbach's alpha reliability coefficient of Albirini's attitude scale was (0.90). Al-Zaidiyeen, Mei, and Fook (2010) also used this scale and reported Cronbach's alpha reliability coefficients above 0.80 .

The second section measured perceived ease of use by means of five-point Likert-type scale from "strongly disagree" (1) to "strongly agree" (5), comprised four items. The items had been adopted from Davis (1989). Four statements evaluated perceived usefulness. Davis (1989) developed this measurement and it was a fivepoint Likert-type scale-like perceived usefulness. Davis's (1989) perceived ease of use and perceived usefulness questionnaire was used by Adam and Wood (1999), and they found that it was entirely valid and reliable. Other researchers such as Doll, Hendrickson, and Deng (1998), Subramanian (1994), and Venkatesh (2000) also used this instrument in their studies. All of them reported reliability coefficients above 0.70 .

The twelve items that measured subjective norms were adopted from a questionnaire developed by Marcinkiewicz and Regstad (1996). In this questionnaire, important people who might influence teacher's attitudes, had been classified into administrators, colleagues, and students. A set of four items was made for each referent group. Responses were scored on a five-point Likert-type scale from (A) not at all; (B) seldom; (C) not sure; (D) frequently; and (E) to a large extent. Delice (2009) used this scale in his work and reported a reliability coefficient of $(r=.85)$.

The trialability questionnaire section was adapted from a study by Ntemana and Olatokun (2012). This variable had five questions. This questionnaire had been used in many previous works. In answering items, teachers had utilized these options: Strongly Disagree $(S D)=1$ : Disagree $(D)=2$ : Agree $(A)=3$ and Strongly Agree $(S A)=4$. Yunus (2014) also used this scale in his work which focused on a component of innovation diffusion theory and found that it was reliable and valid.

\begin{tabular}{|l|c|}
\hline Variable & $\begin{array}{c}\text { Cronbach's } \\
\text { alpha reliability }\end{array}$ \\
\hline Perceived ease of use & 0.84 \\
\hline Perceived usefulness & 0.76 \\
\hline Attitude & 0.80 \\
\hline Subjective norm & 0.78 \\
\hline Trialability & 0.82 \\
\hline
\end{tabular}

Table 1. Cronbach`s alpha reliability

The Cronbach's reliability coefficient alpha test was used in determining the reliability of the questionnaire. The value ranges between 0 and 1.0, with a higher value indicating higher reliability among the indicators. This test was conducted with pilot data from 30 teachers. The purpose of this pilot test was to estimate the instrument stability over a variety of conditions. Cronbach's reliability coefficient alpha provides a measure of the internal consistency of the items. The reliability of all variables in the questionnaire was found to be above 0.75 .

Construct validity of the measure should have been investigated too. Construct validity 
measures an intended hypothetical construct. In this study, construct validity was established by the previously reported analysis in the literature and also by consulting two experts in the field of communication and information technology. Their comments were very valueble to clarifying the instrument to arrive at the final version. They confirmed the content and the relatedness of each item with what was predicted to evaluate.

\section{Data Collection Procedure}

Participants from different schools completed the questionnaires provided by the researcher. The questionnaires were delivered in person to each participant or group of participants (when two or more sample teachers were from the same school). This procedure was necessary to avoid a low response rate. The teachers were given enough time to complete the questionnaires. All participants were informed of the purpose of this study and their rights not to participate in the study. In the next step, the researcher coded data collected by using the questionnaire. The data were recorded first on SPSS software (version 18). A random sample of five percent of the entered data was checked for coding accuracy.

\section{Data Analysis}

In the data analysis step, the proposed research model and research hypothesis were tested. This involved using a model which could assess the contribution and significance of the variables. This research attempted to identify the causes of greater instructional technology use. Consequently, path analysis, a form of causal modeling, was chosen as the statistical procedure for examining the relationship between teacher perceptions and the use of instructional technology. Causal modeling techniques examine whether a pattern of Interco-relations among variables "fits" the underlying theory regarding which variables are influencing other variables (Byrne, 2013).

\section{Findings and Discussion}

In the present study, path analysis, a form of causal modeling, is selected as the statistical procedure for examining the relationship between teacher perceptions and the use of instructional technology. Causal modeling techniques examine whether a pattern of Interco-relations among variables "fits" the underlying theory regarding which variables are influencing other variables. The first step in a path analysis is to examine the Goodness of Fit, which means how well the proposed model fits the real data. That means the hypotheses of the model should fit the collected data (Byrne, 2013).

\begin{tabular}{|l|l|}
\hline Modification index & Value \\
\hline GFI & 0.991 \\
\hline AGFI & 0.869 \\
\hline NFI & 0.968 \\
\hline CFI & 0.975 \\
\hline RMSEA & 0.086 \\
\hline X2 & 2.529 \\
\hline DF & 1 \\
\hline P & 0.060 \\
\hline
\end{tabular}

Table 2. Modification index 
In Table 2, the reported root means square residual of approximation (RMSEA) is 0.086, i.e., less than 0.1 , which indicates a good fit. Other indications that the model fits well are the comparative fit index (CFI), which is 0.975 , the goodness of fit index (GFI), which is 0.991, the adjusted goodness of fit index (AGFI), which is 0.869 , and the null fit index which is 0.964 . Values are much larger than the common target of 0.9 for reflecting a good fit. Thus, it is concluded that the proposed model fits well and represents a reasonably close approximation in the population.

After assessing the goodness of fit of the proposed model, the hypothesized relationships between the variables are evaluated. The

\begin{tabular}{|c|c|c|c|c|}
\hline $\begin{array}{c}\text { Dependent } \\
\text { variables }\end{array}$ & $\begin{array}{c}\text { Independent } \\
\text { variables }\end{array}$ & $\begin{array}{c}\text { Path } \\
\text { coefficient }(\beta)\end{array}$ & T-values & Finding \\
\hline PEU & Tri & 0.21 & 2.815 & supported \\
\hline PEU & SN & 0.32 & 4.208 & supported \\
\hline PU & Tri & 0.19 & 2.546 & supported \\
\hline PU & SN & 0.26 & 3.447 & supported \\
\hline ATT & Tri & 0.38 & 5.442 & supported \\
\hline ATT & PU & 0.26 & 3.666 & supported \\
\hline ATT & PEU & 0.16 & 2.199 & Supported \\
\hline PU & PEU & 0.22 & 2.805 & Supported \\
\hline
\end{tabular}

Table 3. Path analysis result

In Table3, the first row indicates the direct effect of trialability on perceived ease of use $(\beta=0.21, T=2.815)$. Because the value of $T$ is equal to 2.815 , which is greater than 1.96 , the direct effect of trialability on perceived ease of use (0.21) is significant at 0.05 level. The second row indicates the direct effect of subjective norm on perceived ease of use $(\beta=0.32$, $T=4.208$ ). Because the value of $T$ is equal to 4.208, which is greater than 1.96 , the direct standardized path coefficient, T-value, and Pvalue are assessed to test the relationships among variables. In this study, P-value is used to assess how statistically meaningful the relationships between measured variables at the level 0.05 are. The standardized path coefficient $\beta$ means the path demonstrates a causal relationship between two variables (Hair, Black, Babin, \& Anderson, 2010). It is used to calculate the size of the different constructs in the model. Variables' values are estimated using T-value. Tvalue can be assessed by dividing the regression coefficient ( $\beta$ ) by the standard error (SE), and it is considered significant at the 0.05 level if the Tvalue is equal to or above 1.96 (Hair et al., 2010). effect of subjective norm on perceived ease of use (0.32) is significant at 0.05 . The third row indicates the direct effect of trialability on perceived usefulness $(\beta=0.19, T=2.546)$. Because the value of $\mathrm{T}$ is equal to 2.546 , which is greater than 1.96, the direct effect of trialability (0.19) on perceived usefulness is significant at 0.05 level.

The fourth row indicates the direct effect of subjective norm on perceived usefulness 
$(\beta=0.26, T=3.447)$. Because the value of $T$ is equal to 3.447 , which is greater than 1.96 , the direct effect of the subjective norm (0.26) on perceived usefulness is significant at 0.05 level. Corresponding to Table 3, perceived usefulness ( $\beta=0.26, T=3.666)$ and perceived ease of use $(\beta=0.16, T=2.199)$ have a meaningful and direct effect on attitude toward the use of technology. In this table, the biggest direct effect relates to trialability on attitude $(\beta=0.38, T=5.442)$. Because the value of $\mathrm{T}$ is equal to 5.442 , which is greater than 1.96 , the direct effect of trialability (0.38) on attitude is significant at 0.05 level.

Table 4 illustrates the correlation among variables. The correlation of all variables with the predisposition of technology acceptance is validated by meaningful significance $(P<0.05)$.

\begin{tabular}{|l|c|l|l|l|l|}
\hline & Attitude & trialability & Ease of use & Usefulness & Subjective. Norm \\
\hline Attitude & 1 & & & & \\
\hline trialability & $.406^{* *}$ & 1 & & & \\
\hline Ease.of.use & $.161^{*}$ & $.170^{*}$ & 1 & & \\
\hline Usefulness & $.377^{* *}$ & $.187^{*}$ & $.260^{* *}$ & 1 & \\
\hline $\begin{array}{c}\text { Subjective. } \\
\text { Norm }\end{array}$ & $.302^{* *}$ & .130 & $.288^{* *}$ & $.350^{* *}$ & 1 \\
\hline
\end{tabular}

\section{Table 4. Correlation matrix}

The highest amount of correlation belonged to attitude and trialability (0.406). Meanwhile, norm and trialability (0.130). Other correlations the lowest amount was between subjective 


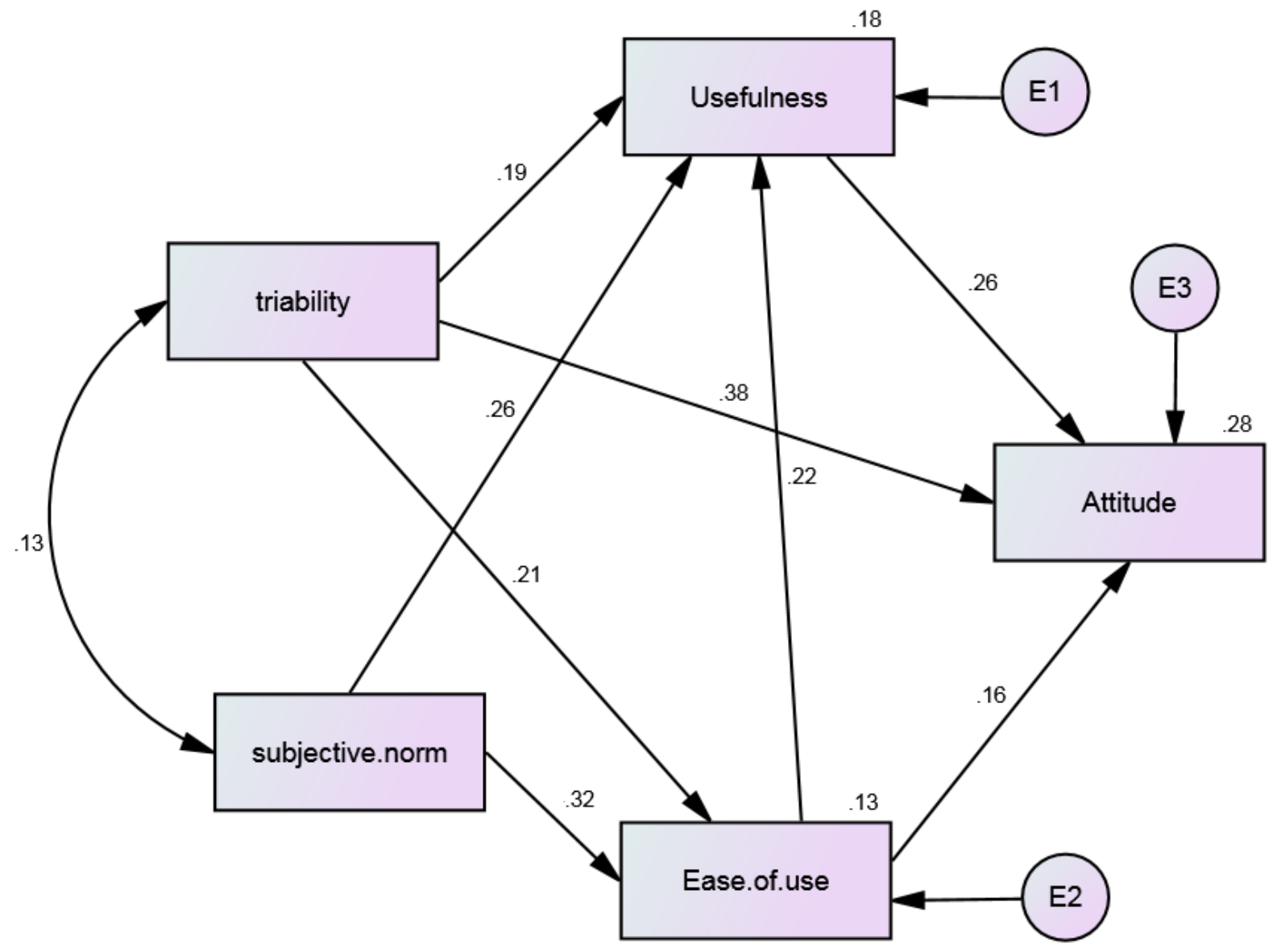

Figure 2. Fitted model

\section{Conclusion}

Nowadays, with the vast use of technology in every situation, the importance of technology acceptance is inevitable. The hypothesized research model was driven based on the literature and stated in the form of the research hypotheses. According to the present study results, the correlation between variables is acceptable, and it indicates a significant and positive relationship among variables. The present study's findings are in line with Rabaa'i (2018), and Tri Anni et al. (2018), which emphasized the effect of perceived ease of use and perceived usefulness on attitude toward technology use. The present study's findings aligned with Rabaa'i (2018) and Park (2009) which explained the impact of subjective norm and trialability on perceived ease of use. Also, the present study's findings are in accordance with Dastorani and Khoshneshin (2017) and Jung (2015), which confirmed the effect of subjective norm and perceived ease of use on perceived usefulness. Technology and technology-based environments may have a great potential in promoting socio-economic changes in different countries. In Iranian high schools, which will boost their educational systems, it is suggested to establish a suitable environment physically and practically for both students and teachers to interact technology with ease in minimum time. 
The research results indicated that perceived ease of use was an influential variable in the research model. It means that when teachers perceive that the use of a computer is easy, they are motivated to apply it in teaching. Therefore, it is suggested that school administrators select and buy systems that are not complicated for teachers. Perceived usefulness has a direct effect on attitude. It is recommended that the benefits of using technology in teaching are explained to teachers. For example, it could be said that it is very useful in improvement of the quality of teaching and also in students' achievement in comparison with traditional tools. Subjective norm has an indirect but important effect on attitude. When using technology in teaching is encouraged by school administrators and teachers' colleagues, teachers are more likely to use it in their instruction. It is recommended that school administrators support teachers financially. It is suggested that psychological courses be held for teachers to improve their awareness in using technology.

\section{References}

Adam, L., \& Wood, F. (1999). An investigation of the impact of information and communication technologies in sub-Saharan Africa. Journal of Information Science, 25(4), 307-318. https://doi.org/10.1177/016555159902500 407

Agarwal, R., \& Prasad, J. (1997). The Role of Innovation Characteristics and Perceived Voluntariness in the Acceptance of Information Technologies. Decision Sciences, 28(3), 557-582. https://doi.org/https://doi.org/10.1111/j.15 40-5915.1997.tb01322.x
Al-Zaidiyeen, N. J., Mei, L. L., \& Fook, F. S. (2010). Teachers' Attitudes and Levels of Technology Use in Classrooms: The Case of Jordan Schools. International Education Studies, $3(2)$, p211. https://doi.org/10.5539/ies.v3n2p211

Albirini, A. (2006). Teachers' attitudes toward information and communication technologies: the case of Syrian EFL teachers. Computers \& Education, 47(4), 373-398. https://doi.org/https://doi.org/10.1016/j.co mpedu.2004.10.013

Bourgonjon, J., De Grove, F., De Smet, C., Van Looy, J., Soetaert, R., \& Valcke, M. (2013). Acceptance of game-based learning by secondary school teachers. Computers and Education, 67, 21-35. https://doi.org/10.1016/j.compedu.2013.02. 010

Byrne, B. M. (2013). Structural equation modeling with AMOS: Basic concepts, applications, and programming, second edition. In Structural Equation Modeling with AMOS: Basic Concepts, Applications, and Programming, Second Edition. https://doi.org/10.4324/9780203805534

Dastorani, M., \& Khoshneshin, Z. (2017). An Analytic Review on the Factors that Affect Technology Acceptance Model (TAM) in Iranian Universities. Interdisciplinary Journal of Virtual Learning in Medical Sciences, In Press. https://doi.org/10.5812/ijvlms.56028

Davis, F. D. (1989). Perceived Usefulness, Perceived Ease of Use, and User Acceptance of Information Technology. MIS Quarterly, 13(3), 319-340. https://doi.org/10.2307/249008

Delice, M. (2009). Explanation of police officers' information technology acceptance using the 
technology acceptance model and social cognitive theory.

Doll, W., Hendrickson, A., \& Deng, X. (1998). Using Davis's Perceived Usefulness and Ease-of-use Instruments for Decision Making: A Confirmatory and Multigroup Invariance Analysis. Decision Sciences, 29, 839-869. https://doi.org/10.1111/j.1540-

5915.1998.tb00879.x

Hair, J., Black, W., Babin, B., \& Anderson, R. (2010). Multivariate Data Analysis: A Global Perspective.

Isaac, O., Abdullah, Z., Ramayah, T., Mutahar, A., \& Alrajawy, I. (2016). Perceived Usefulness, Perceived Ease of Use, Perceived Compatibility, and Net Benefits: an empirical study of internet usage among employees in Yemen.

Jung, H.-J. (2015). Fostering an English Teaching Environment: Factors Influencing English as a Foreign Language Teachers' Adoption of Mobile Learning. Informatics in Education, 14, 219-241. https://doi.org/10.15388/infedu.2015.13

Junhong, L. (2009). A Survey of EFL Learners' Attitudes toward Information and Communication Technologies. English Language Teaching, 2. https://doi.org/10.5539/elt.v2n4p101

Krejcie, R., \& Morgan, D. (1970). Determining Sample Size for Research Activities. Educational and Psychological Measurement - EDUC PSYCHOL MEAS, 30, 607-610. https://doi.org/10.1177/001316447003000 308

Lee, Y.-H., Hsieh, Y.-C., \& Hsu, C.-N. (2011). Adding Innovation Diffusion Theory to the Technology Acceptance Model: Supporting Employees' Intentions to use E-Learning
Systems. Educational Technology \& Society, 14, 124-137.

Marcinkiewicz, H., \& Regstad, N. (1996). Using Subjective Norms To Predict Teachers' Computer Use. Journal of Computing in Teacher Education, 13. https://doi.org/10.1080/10402454.1996.110 08223

Mutahar, A., Norzaidi, M., Ramayah, T., Isaac, O., \& Alrajawy, I. (2017). Integration of Innovation Diffusion Theory (IDT) and Technology Acceptance Model (TAM) to Understand Mobile Banking Acceptance in Yemen: The Moderating Effect of Income. International Journal of Soft Computing, 12, 164-177.

Nan, Z., Guo, X., \& Chen, G. (2008). IDT-TAM integrated model for IT adoption. Qinghua Daxue Xuebao/Journal of Tsinghua University, 13, 306-311. https://doi.org/10.1016/S10070214(08)70049-X

Ntemana, T., \& Olatokun, W. (2012). Analyzing the Influence of Diffusion of Innovation Attributes on Lecturers' Attitude Towards Information and Communication Technologies. Human Technology An Interdisciplinary Journal On Humans In ICT Environments, $\quad 8, \quad$ 179-197. https://doi.org/10.17011/ht/urn.201211203 034

Park, S. Y. (2009). An Analysis of the Technology Acceptance Model in Understanding University Students' Behavioral Intention to Use e-Learning. Educational Technology \& Society, 12, 150-162.

Rabaa'i, A. (2018). Extending the Technology Acceptance Model (TAM) to assess Students' Behavioural Intentions to adopt an eLearning System: The Case of Moodle as a Learning Tool. 
Rogers, E. M. (1995). Diffusion of Innovations (4th Edition). New York: Free Press.

Shiau, S., Huang, C.-Y., Yang, C.-L., \& Juang, J.-N. (2018). A Derivation of Factors Influencing the Innovation Diffusion of the OpenStreetMap in STEM Education. Sustainability, $10, \quad 3447$. https://doi.org/10.3390/su10103447

Smith, J. (2006). The Effect Of Social Presence On Teacher Technology Acceptance, Continuance Intention, And Performance In An Online Teacher Professional Development Course.

Subramanian, G. (1994). A Replication of Perceived Usefulness and Perceived Ease of Use Measurement*. Decision Sciences, 25, 863$874 . \quad$ https://doi.org/10.1111/j.15405915.1994.tb01873.x

Tran, T. C. T., \& Cheng, M. S. (2017). Adding Innovation Diffusion Theory to Technology Acceptance Model: Understanding Consumers' Intention to Use Biofuels in Viet Nam. International Review of Management and Business Research, 6, 595.

Tri Anni, C., Sunawan, S., \& Haryono, H. (2018). School Counselors' Intention to Use Technology: The Technology Acceptance
Model. Turkish Online Journal of Educational Technology, 17.

Venkatesh, V. (2000). Determinants of Perceived Ease of Use: Integrating Control, Intrinsic Motivation, and Emotion into the Technology Acceptance Model. Information Systems Research, 11, 342-365. https://doi.org/10.1287/isre.11.4.342.11872

Venkatesh, V., \& Davis, F. (2000). A Theoretical Extension of the Technology Acceptance Model: Four Longitudinal Field Studies. Management Science, 46, 186-204. https://doi.org/10.1287/mnsc.46.2.186.119 26

Wingo, N., Ivankova, N., \& Moss, J. (2017). Faculty Perceptions about Teaching Online: Exploring the Literature Using the Technology Acceptance Model as an Organizing Framework. Online Learning, 21. https://doi.org/10.24059/olj.v21i1.761

Yunus, M. (2014). Information and Knowledge Management Diffusion of Innovation, Consumer Attitudes and Intentions to use Mobile Banking. Information and Knowledge Management, 4(10), 12-18. Retrieved from www.iiste.org 
Somaye Davoodi, Leila Akbarpour, Ehsan Hadipour 